\title{
Geotechnical consideration regarding the routing of twin railway tunnels across the Karoun River
}

\author{
B. Esmaeili ${ }^{1}$, A. A. Safikhani ${ }^{2}$ \& A. A. Amiri Samani ${ }^{2}$ \\ ${ }^{1}$ Engineering Department of Kayson Company, Iran \\ ${ }^{2}$ Ahwaz Urban Railway Project, Kayson Company, Iran
}

\begin{abstract}
Ahwaz city is located in the Khoozestan Province, a floodplain, almost flat area on the south western margin of the Zagros mountain range, well known by its giant oil fields. The four main geological phenomena of this area are: the Ahwaz fault, the Ahwaz anticline, the Aghajari formation and the alluvium deposits of Quaternary. Karoun, the biggest river of Iran, runs through this city. The Ahwaz Urban Railway Project was started in 2006 (the engineering, procurement and construction (EPC) contractor is Kayson Company). About 100 bore holes were drilled along the project, and the main problem was how to cross the river. Due to the city condition (streets, buildings...) the tunnels should pass under the river, but where and at what depth is the question. The agglomeration of people and transportation system were dictated by the zone of river crossing but in order to find the exact location and depth of the tunnels, complete studies were undertaken.
\end{abstract}

\section{Introduction}

Ahwaz city is located in the south west of Iran as the centre of the Khuzestan Province with a population of about 2 million. The Ahwaz Urban Railway Project consists of a 24-kilometre parallel twin tunnel with a 6 metre final radius and 24 stations. The project level is $-17.5 \mathrm{~m}$ from the surface, except for the crossing with the Karoun River (the tunnels crossing under the Karoun River at a lower elevation) and the water level is about $-2 \mathrm{~m}$ from the surface [1]. Twin tunnels would be drilled by a tunnel boring machine (TBM). Therefore, some boreholes with a complete set of laboratory and field tests were drilled on the 
route and at stations. Ten boreholes were drilled inside the river and ten more were drilled on the river banks. As the geological map shows, the crossing of tunnels with the river was located in the Ahwaz fault zone.

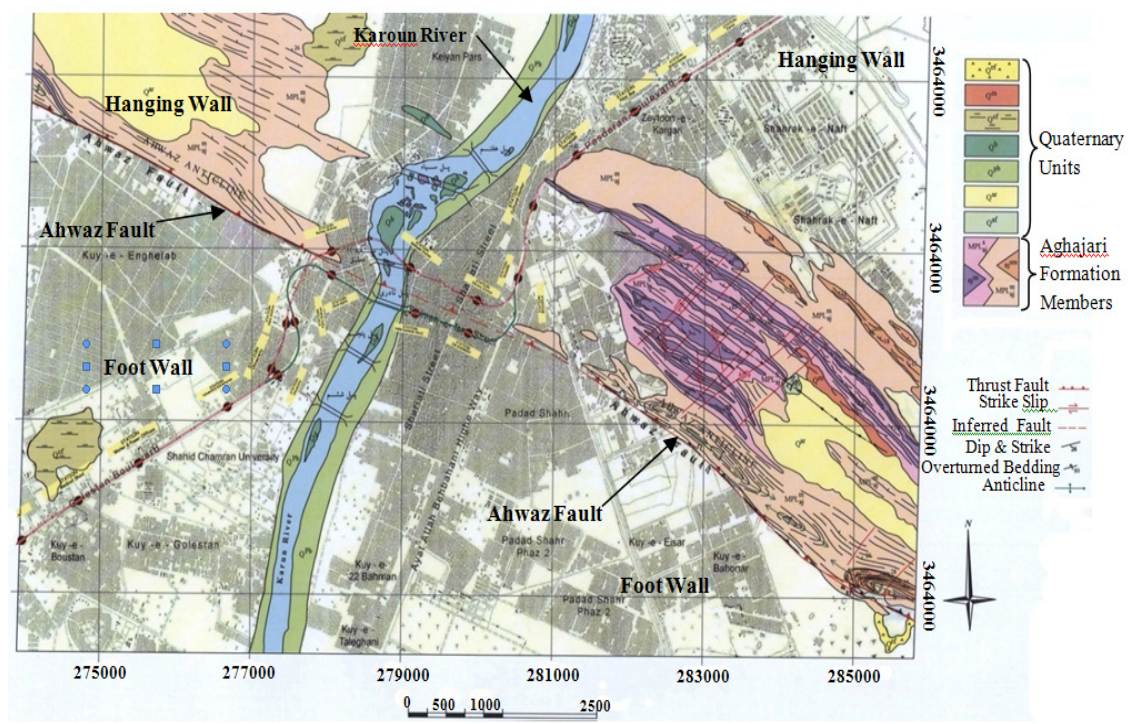

Figure 1: Geological map of Ahwaz city in the crossing area of project routes with the river [2].

\section{Aghajari formation}

The Aghajari formation consists of brown-grey calcareous sandstone, silt stone and clay stone with gypsum veins. The thickness of the formation in the type section is 2965 metres. The formation age is from the Miocene to the Pliocene period [3]. In the Ahwaz city area, bed rock is sequence layers of sandstone, siltstone and clay stone.

\section{Young Quaternary sediments}

The young Quaternary sediments have been spread widely in the Ahwaz area. These sediments have been transferred and deposited by river flow and great floods during the Quaternary period. Precipitating in the area has been done and controlled by the Karoun River as the main factor for carrying sediments due to the erosion of the river basin. The upper layer of sediments in the banks and basin of Karoun are medium grained sands with some silt and clay (of about 10 to 20 metre thickness). Under the sandy layer, in the hanging wall area of the Ahwaz fault the Aghajari lithified formations are located, but in the footwall area, fine grained silt-clay sediments were deposited. The variation of deposits in 
the crossing area has been controlled by the speed and hydrodynamic regime of the Karoun River which has been affected by the fault.

\section{Ahwaz fault}

The Ahwaz fault is a reverse type with about $100 \mathrm{~km}$ length, in a northwest to southeast direction and a slope towards the northeast. The fault passes through the city centre, parallel with the Ahwaz unsymmetrical overturned anticline. The dip of the northeast flank of the anticline is about 15 degrees towards northeast, but the dip of the southwest overturned flank is about 75-80 degrees towards northeast. Torabi and Ghasemi have called this the Ahwaz foreland fault [4] and McQuarrie believed the Ahwaz fault is the forehead fractural structure of the Zagros mountain range [5]. The recently published Active Fault Map of Iran addresses the Ahwaz fault as an active type, which is supported by several earthquakes. Our studies indicate that active tectonic caused longitudinal and lateral tilting in the Karoun River and development of significant features of sedimentation on the crossing with the river.

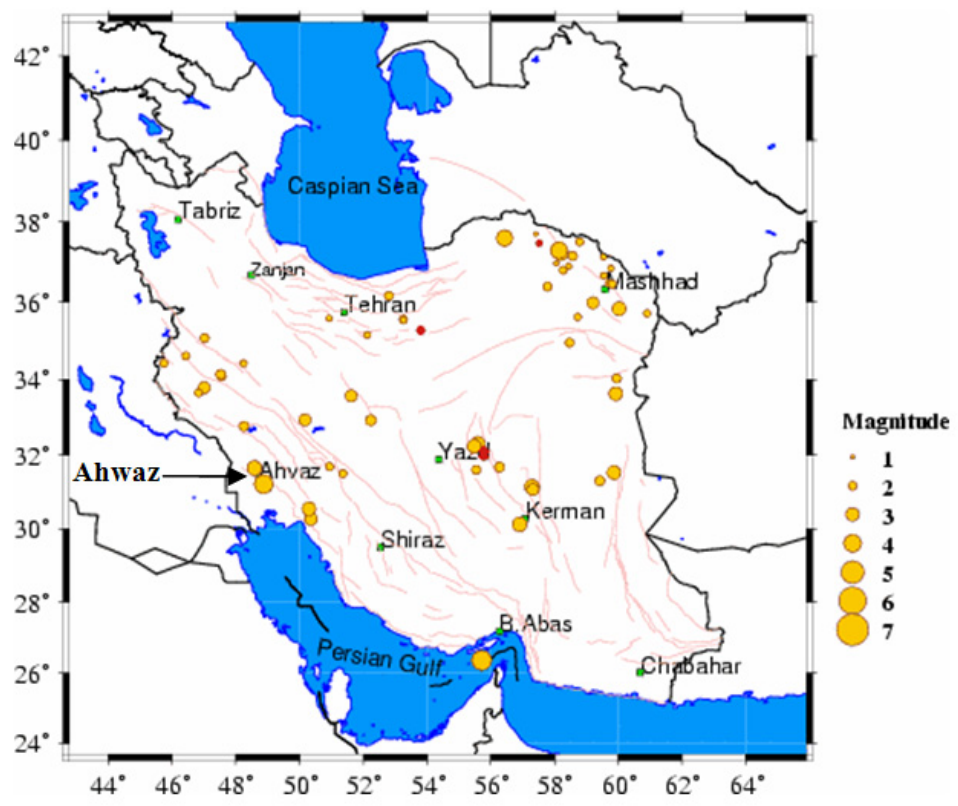

Figure 2: Quaternary active faults in Iran. As shown, Ahwaz is located on the active fault with recorded earthquakes in recent years [6]. 


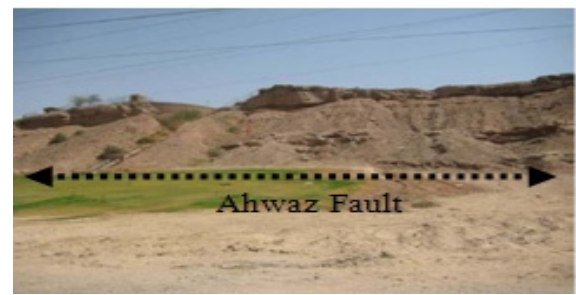

Figure 3: Aghajari formation, Ahwaz thrust fault and young Quaternary sediments in the eastern part of Ahwaz city. Such morphology as this is located under the Karoun River in the crossing area with the Ahwaz fault. This land form worked as a stilling basin under the river.

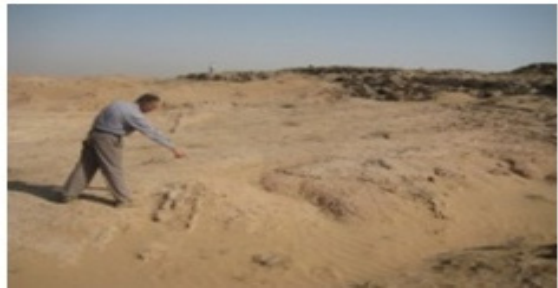

Figure 4: The boundary of the Aghajari formation and young Quaternary sediments at Ahwaz fault, $30 \mathrm{~km}$ east of the city [7].

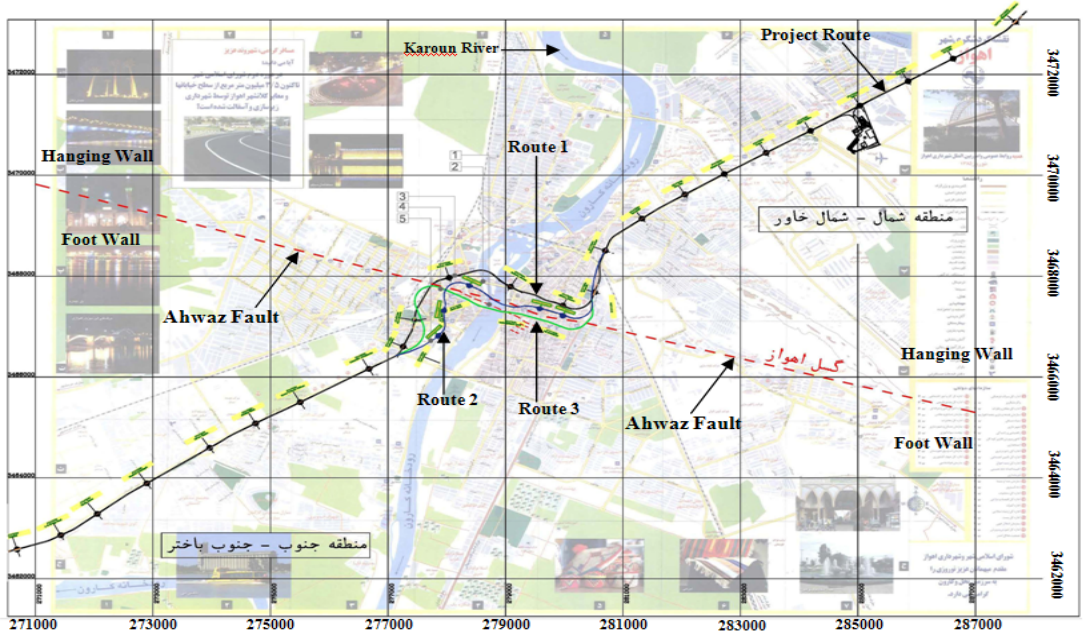

Figure 5: $\quad$ Ahwaz city map and Routes 1, 2 and 3. 


\section{Geological and geotechnical studies}

The main problem is to select an area for the tunnels to cross the river to be as shallow as possible with regard to the agglomeration and traffic system. (If the depth of the tunnels increases, the cost of construction and operation will increase too). In primary studies two routes were selected to cross Karoun River. Route 1 was located on the north part of crossing of Ahwaz fault and Karoun (in the hanging wall) and the Route 2 was located on the south part of that crossing (in the foot wall). The depth of river water is nearly the same in both routes. The sediments of river bed were started with young, loose, unconfined, coarse grain sands on both routes. At Route 1, the Aghajari formation was located under the sands but at Route 2 the compacted, impermeable fine grained silt-clay sediments were located under the sandy layer [8]. With regard to geotechnical results, the young loose sandy layer is not suitable to be encountered with tunnels, even by (TBM). So the depth of tunnel must be increased in order to reach the suitable lithology for drilling (Aghajari Formation at Route 1 and compacted silt-clay sediment at Route 2). Beside the geotechnical research, the routes of the project were studied from the agglomeration and number of passenger transportation points of view. The conclusion shows that Route 2 is completely preferred over Route 1 , but the thickness of loose sandy sediments in Route 2 is more than at Route 1 . So the level of that is located at a lower and deeper elevation and costs more during construction and operation. Then the engineering team concentrated on the Route 2 area with more geotechnical and geological studies. The location of Route 2 is about 100 meters south of the Ahwaz fault. This fault has thrust Aghajari formation over young Quaternary alluvium and bed rock was settled totally in the south part of the fault. So a big trench has been created near and parallel to the fault in the foot wall area and has been working like a stilling basin which has been filled by coarser and weightier sandy sediments. So, along the south direction, the depth of this trench

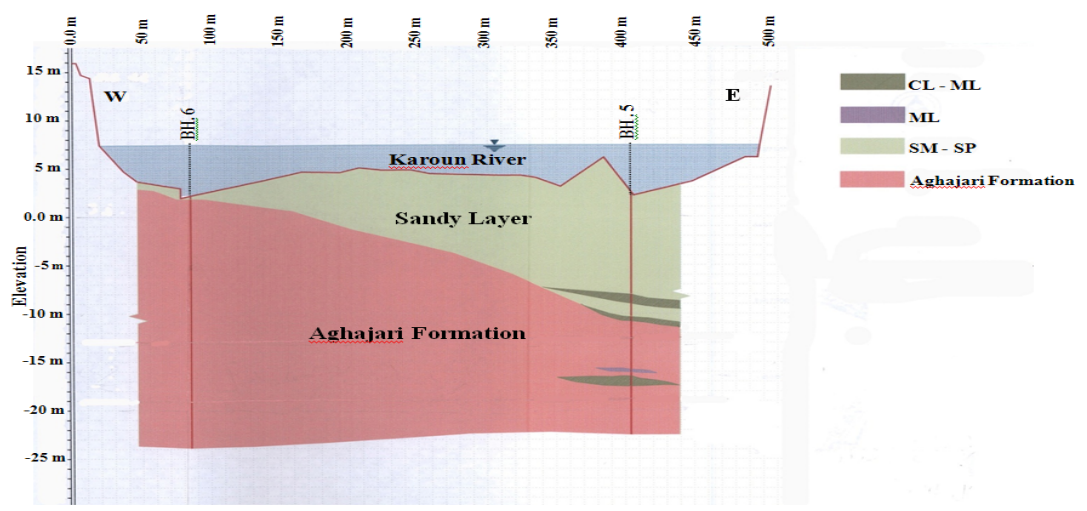

Figure 6: Subsurface cross section on Route 1, the pink colour shows bed rock and green is sandy sediments [8]. (See online for colour version.) 
and thickness of the sandy layer decreases, and then if the route of project moves to the south, it would be located in a higher elevation inside compacted silt-clay sediments. This idea was proved by drilling six boreholes in the south part of Route 2 . Then the route was moved about 60 meters to the south.

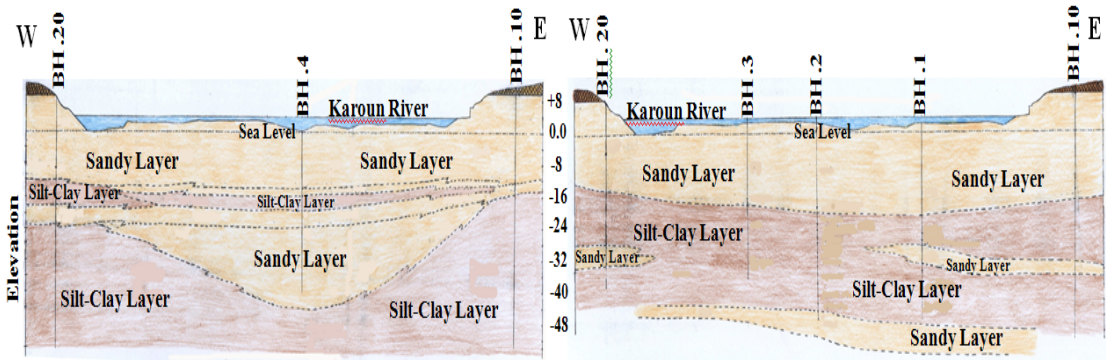

Figure 7: Subsurface cross sections on Route 2. Both sections are located in the foot wall area but the left one is closer to the Ahwaz fault. The left section shows geological layers north of Naderi Bridge and the right shows south of Naderi Bridge. The thickness of the sandy layer in the north (left section) is much more than in the south (right section) [8].

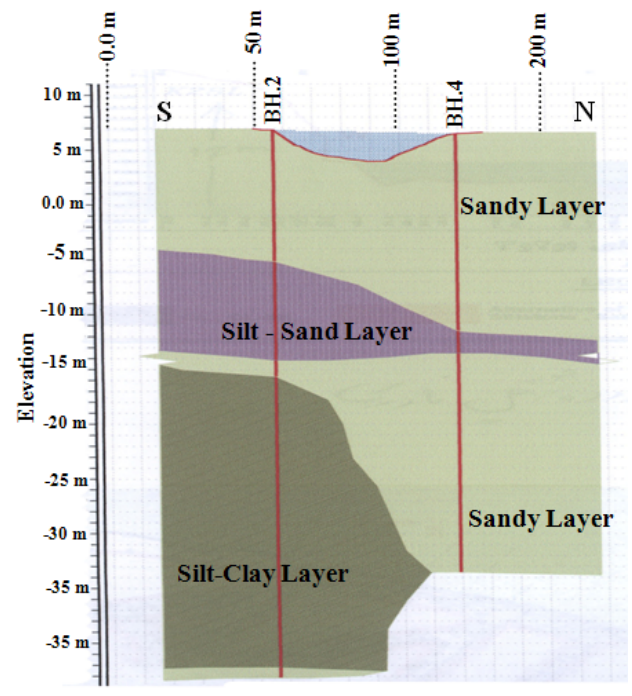

CL - MI

Aghajari Formation

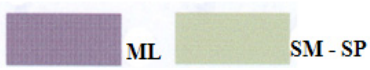

Figure 8: Subsurface cross section between $\mathrm{BH} 4$ and $\mathrm{BH} 2$ (from north to south, along the river). The thickness of the sandy layer decreases from north to south in a short distance (light green colour). After study of these sections (figures 7 and 8), the engineering team decided to focus on Route 3 at the south part of Route 2 [8]. 
As a result of this change, the tunnels' route is located inside safe compacted impermeable silt-clay sediments (Route 3 ) and the design team succeeded in decreasing the elevation of tunnels and stations (at least two stations) at both sides of the river and finally saved huge amounts of costs during the construction and operation period.

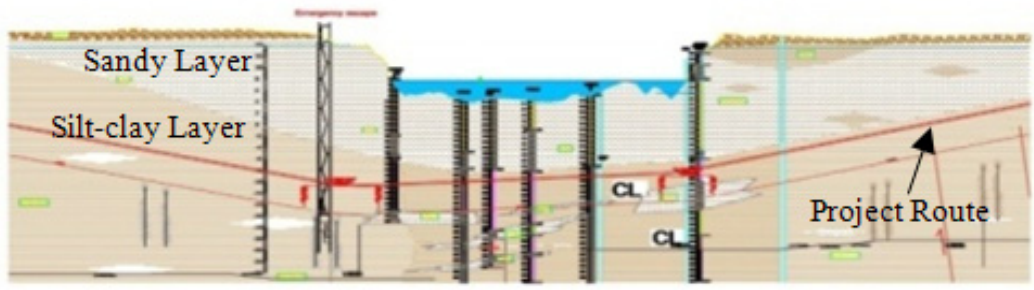

Figure 9: $\quad$ Subsurface cross section on Route 3. The project line passes under river without encountering the sandy layer [8].

\section{Conclusion}

During site selection and routing of civil projects, geological and geotechnical conditions mostly dictate fundamental and basic concepts. Therefore, the engineering and design of civil projects is not only a science but also an art. The greatest challenge in this project is how to pass the river as easy and as operational as possible - construction vies with the lowest cost and in the shortest time. This corridor must be passed in the most crowded zone of the city and gives the most services to the passenger transportation system. Naderi Street and Naderi Bridge are located in centre of the most important official, business, and residential zone of the city and would give the best services to the citizens. The project's route at the crossing area with the river was studied in three stages. At the first step, the engineering team tried to recognize the subsurface and surface phenomena by geological and geotechnical studies. Then the information was used to choose the best corridor and depth for the project. Finally, the best route was chosen in the south part of Naderi Bridge. By these studies, the elevation of $3 \mathrm{~km}$ of the tunnels and two stations have been decreased and a huge amount of costs and time have been saved [9].

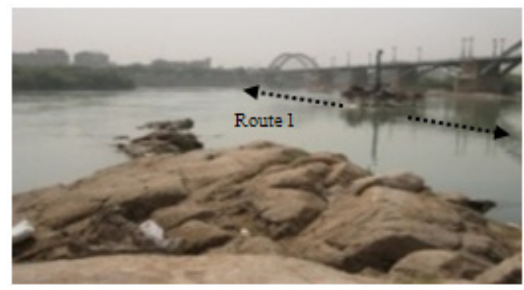

Figure 10: Drilling borehole inside Karoun River on Route 1, north of Pol-eSefid Bridge (hanging wall). This route passes through the Aghajari formation. 


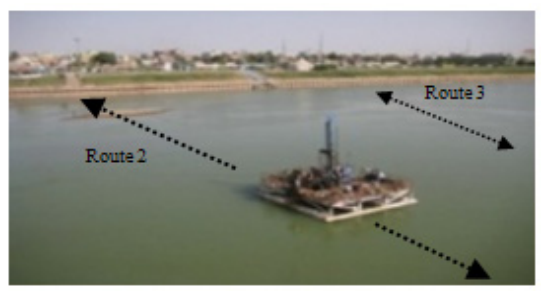

Figure 11: Drilling borehole inside the river on Routes 2 and 3, south of Naderi Bridge (foot wall). This picture shows the location of Routes 2 and 3.

\section{References}

[1] Esmaeili B. Hydrogeology Report of Ahwaz city, 2008.

[2] Geological Survey of Iran, Ahwaz 1:50000 geological map, 2008.

[3] Alavi M., Regional Stratigraphy of the Zagros in Iran, American Journal of Science, 2004.

[4] Torabi and Ghasemi, Kinematics Analysis of Reservoir Horizons in the oil fields of Dezful Embayment, Geosciences, 2004.

[5] McQuarrie N., Crustal scale geometry of Zagros fold - thrust belt, Iran, Journal of Structural Geology, 2004.

[6] Hesami Kh, Jamali F., and Tabasi H., Major Active Fault of Iran, 1:2:500,000 scale map, Ministry of Science, Research and Technology, International Institute of Earthquake Engineering and Seismology, Tehran, Iran, 2003.

[7] Zar Zamin Co., Seismic design and analysis and risk assessment of Ahwaz city regarding urban railway project, 2008.

[8] Hesami Kh, Jamali F., and Tabasi H., Major Active Fault of Iran, 1:2:500,000 scale map, Ministry of Science, Research and Technology, International Institute of Earthquake Engineering and Seismology, Tehran, Iran, 2003.

[9] Pey Saman Co., Banian Pey Co., Mandro Co., Darya Khak Pey Co., Geological and geotechnical studies on "Ahwaz Urban Railway Project" reports, 2006-2009.

[10] Samani B. and Esmaeili B., Assessment Report of Route One and Route Two in "Ahwaz Urban Railway Project", 2007. 